\title{
Kinetico-mechanistic studies of substitution reactions on cross-bridged cyclen CoIII complexes with nucleosides and nucleotides $\uparrow$
}

Marta Vázquez, ${ }^{a}$ Mercè Font-Bardia ${ }^{b}$ and Manuel Martínez ${ }^{* a}$

aDepartament de Química Inorgànica, Universitat de Barcelona, Martí i Franquès 1-11, E-08028 Barcelona, Spain.

E-mail: manel.martinez@qi.ub.es

bUnitat de Difracció de RX, Centres Científics i Tecnològics de la Universitat de Barcelona (CCiTUB), Universitat de Barcelona, Solé i Sabarís 1-3, 08028-Barcelona, Spain 
29 Kinetico-mechanistic studies on the substitution reactivity of the $[\mathrm{Co}\{(\mu-\mathrm{ET}) \mathrm{cyclen}\}(\mathrm{H} 2 \mathrm{O}) 2] 3+$

30 complex cation at $\mathrm{pH}$ values within the 6.0-7.0 range with biologically significant ligands have been carried out. The substitution processes have been found to occur exclusively on the monohydroxobridged $[(\mathrm{Co}\{(\mu-\mathrm{ET}) \operatorname{cyclen}\}(\mathrm{H} 2 \mathrm{O})) 2(\mu-\mathrm{OH})] 5+$ species formed after equilibration of the cobalt complex in the relevant medium. The studies conducted on the substitution of the aqua/hydroxo ligands of this dinuclear species are indicative of a dominant role of outer-sphere complexation, involving hydrogen-bonding interactions. The values of the outer-sphere complex formation equilibrium constant are in line with the intervention of both the exiting aqua ligands and the $\mathrm{NH}$ groups at the encapsulating $\{(\mu$-ET $)$ cyclen $\}$ ligand. These complexes result in the preferential formation of $\mathrm{O}$ - or N-bonded nucleotides depending on the structure of the base moiety of the ligand. Even the entry of the different

39 donor bonded nucleotides is hampered by the hydrogen-bonding interaction with the dangling moiety of an already coordinated ligand. In general the overall substitution processes occur at a faster rate than those published for the fully alkylated encapsulating $\{(\mathrm{Me}) 2(\mu$-ET)cyclen $\}$ ligand derivative, as expected for the still available base-catalysing NH groups in the $\{(\mu-\mathrm{ET})$ cyclen $\}$ ligand. 
47 As stated on many occasions, the use of coordination compounds to study possible modification in 48 biologically significant molecules is not new, nevertheless any new information that can be extracted from their simple reactivity should not be underestimated.1,2 Besides obvious thermodynamic requirements and no leaching of the metal centre, the need for the processes to occur at a rate that allows a controlled reaction, should also be taken into consideration when designing systems able to act in biological systems. That is, the solvolysis or substitution processes that involve the metal centres have to be relatively slow in order to ascertain the maintenance of the active molecule, or the interaction of the complex with the expected target. 3 Nevertheless, the use of complexes that behave as dead-end species for kinetic or thermodynamic reasons should also be avoided. A significant amount of literature has been lately appearing dealing with the speciation, hydrolysis, complexation and polymerization of a number of "biologically" active centres, underlining the key role of simple substitution processes actuating on biologically relevant coordination complexes.4-7 Clearly a rationalization of the solution behaviour of metal complexes under conditions similar to those in biological media is fully desirable, including stability in plasma studies. 8 Mimicking in vitro the conditions of biological systems is extremely difficult, if possible at all, so that some simplifications have to be made. In this respect, hydrogen bonding and stabilization of supramolecular interactions have dramatic consequences in many processes expected to be rather simple.9 Another important aspect relates to the effect of temperature on the activity of these coordination compounds, 10 which underlines the importance of determining

Although the anticancer activity of cis-platinum still remains as the most important landmark in medicinal inorganic chemistry, the importance of other metal complexes should not be underestimated.11 The last few decades have seen an increasing number of reports showing metal complexes with promising medical applications and, for example, ruthenium complexes are now one of the most important groups of compounds with antitumor properties.12-17 CoIII complexes with an inert tetradentate skeleton and two reactive positions in cis are obviously interesting as they could represent a cheaper and less toxic alternative to currently used compounds. 18 Even some Co alkyne complexes have shown promising activity associated with their capability to target specific enzymes. 19,20 The use of complexes of type cis-[Co(N)4(H2O)2]3+, with $(\mathrm{N}) 4$ being tren, cyclen or fully alkylated $\{(\mathrm{Me}) 2(\mu-$ ET)cyclen $\}$ has already been explored by us $9,21,22$ by studying their substitution processes with some nucleosides and nucleotides at physiological $\mathrm{pH}$. In this respect there has been an important increase in the use of cross-bridged cyclen and cyclam ligands, both for their promising properties and the robustness of their structure containing five- and six-membered macrocyclic full encapsulation.23-25 Although for the tren and cyclen complexes the existence of fast base-conjugate processes dominate their reactivity,26-29 the use of the fully substituted [Co $\{(\mathrm{Me}) 2(\mu$-ET)cyclen $\}(\mathrm{H} 2 \mathrm{O}) 2] 3+$ produces a definite increase in the inertness of the derivatives, due to the absence of acidic $\mathrm{NH}$ groups. 27 In this respect, the formation and cleavage of hydroxo-bridged dimeric units, kineticomechanistically detected some time ago,30,31 has been found to be a keystone. The prevalence of reasonably reactive dinuclear mono-hydroxo-bridged species is directly related to the presence of these $\mathrm{NH}$ groups, only dead-end $\{(\mathrm{N}) 4 \mathrm{Co}(\mu-\mathrm{OH}) 2 \mathrm{Co}(\mathrm{N}) 4\}$ cores detected at $\mathrm{pH}>7.2$ for the fully alkylated $[\mathrm{Co}\{(\mathrm{Me}) 2(\mu-$ $\mathrm{ET})$ cyclen $\}(\mathrm{H} 2 \mathrm{O}) 2] 3+$ material.

In view of these facts, the study of the complex with the tuned, partially substituted but conformationrigid, $\{(\mu$-ET)-cyclen $\}$ (Scheme 1, top) cyclen-based ligand has been pursued. By the use of this ligand, base-conjugate accelerated substitution processes would still be active at $\mathrm{pH}$ values normally higher than neutrality, once the extremely acidic equatorial NH groups in cyclen have been substituted.29 Furthermore, the presence of acidic hydrogens attached to the axial nitrogen donors should also allow some of the interactions observed for the $[\mathrm{Co}($ cyclen $)(\mathrm{H} 2 \mathrm{O}) 2] 3+$ complex 9 with Good's buffer media,32 as well as in $\mathrm{ZnII}$ complexes with nucleotides.33 In this report we present the study of the spontaneous 
94 solution chemistry of $[\mathrm{Co}\{(\mu-\mathrm{ET}) \operatorname{cyclen}\}(\mathrm{H} 2 \mathrm{O}) 2] 3+$ in a $\mathrm{pH}$ range close to neutrality, as well as the 95 kinetico-mechanistic studies on its substitution reactivity with chloride, inorganic phosphate and the 96 nucleosides and nucleotides indicated in Scheme 1. The results collected agree with the reactivity of the 97 CoIII t2g 6 metal centre in dinuclear $[\{\mathrm{Co}\{(\mu-\mathrm{ET})$ cyclen $\}-(\mathrm{H} 2 \mathrm{O})\} 2(\mu-\mathrm{OH})] 5+$ units. The processes are 98 also slightly accelerated, with respect to those observed for the fully substituted $\{(\mathrm{Me}) 2(\mu$-ET)cyclen\} 99 analogue, by the actuation of a base-conjugate pathway. Reactivity stops at $\mathrm{pH}>7.5$, where the 100 prevalence of the bis-hydroxo dimeric form of the ion occurs. The data collected are also indicative of 101 important outer-sphere interactions between the donors on the nucleobase moieties and both the 102 remaining $\mathrm{NH}$ axial groups of the encapsulating ligand, and the aqua ligands on the CoIII coordination 103 centre. 


\section{Solution behaviour of $[\mathrm{Co}\{(\mu-\mathrm{ET}) \operatorname{cyclen}\}(\mathrm{H} 2 \mathrm{O}) 2] 3+$ in the $5.5-7.5 \mathrm{pH}$ range}

108

The diaquo $[\mathrm{Co}\{(\mu$-ET)cyclen $\}(\mathrm{H} 2 \mathrm{O}) 2] 3+$ complex has been obtained for the first time in this work as a triflate salt, and XRD analyses of the compound has also been carried out (Fig. 1). Distances and angles determined for the cation complex do not show any significant difference with those from the cyclen34 and $\{(\mathrm{Me}) 2(\mu-\mathrm{ET})$ cyclen $\} 18$ related complexes. The values of the two $\mathrm{pKas}$ for this species have been determined, both by potentiometric and spectrophotometric $\mathrm{NaOH}$ titrations at $\mathrm{I}=1.0(\mathrm{NaClO} 4)$, as 5.1 and 7.4 at $25{ }^{\circ} \mathrm{C}$, as indicated in the Experimental section. With these values in hand, the species present in the $\mathrm{pH}$ margin of our kinetic studies are $[\mathrm{Co}\{(\mu$-ET)cyclen $\}(\mathrm{H} 2 \mathrm{O})(\mathrm{OH})] 2+$ and $[\mathrm{Co}\{(\mu-$ ET)cyclen $\}(\mathrm{OH}) 2]+$. Determination of these $\mathrm{pKa}$ values using different $\mathrm{pH}$ equilibration times (i.e. 10 70 seconds) was also carried out with the same outcome, thus indicating that the processes being measured correspond effectively to the deprotonation equilibria with no significant intervention of secondary processes. Once the acid/base prevalent species at physiological $\mathrm{pH}$ was established, the possible polymerization processes occurring due to the generation of bridging hydroxo ligands on increasing the $\mathrm{pH}$ was pursued.9,22,28,35 Studies conducted on $(5-10) \times 10-4 \mathrm{M}$ solutions of the $[\mathrm{Co}\{(\mu-\mathrm{ET})$ cyclen $\}(\mathrm{H} 2 \mathrm{O}) 2] 3+$ complex, in non-buffered final $\mathrm{pH}=7.5$, show a set of two step changes in the UV-Vis spectrum on the 30 minute time-scale. By comparison with the previous solution chemistry of the parent $[\mathrm{Co}(\mathrm{cyclen})(\mathrm{H} 2 \mathrm{O}) 2] 3+$ and the fully alkylated $[\mathrm{Co}\{(\mathrm{Me}) 2(\mu-\mathrm{ET})-$ cyclen $\}(\mathrm{H} 2 \mathrm{O}) 2] 3+$ complexes, 9,22 the reactions have been associated with the sequential formation of mono- and bis-hydroxobridged, $[(\mathrm{Co}\{(\mu-\mathrm{ET}) \mathrm{cyclen}\}) 2(\mu-\mathrm{OH}) 2] 4+$, complexes.

By the use of MES and HEPES buffers, a pH screening of this spontaneous solution reactivity has been conducted. In all cases the mentioned UV-Vis spectral changes are reproducible (Fig. S1 $\dagger$ ), and show the two-step sequence indicated above. The time-scale of these processes ( 10 plus 70 minutes at $\left.17^{\circ} \mathrm{C}\right)$ is clearly intermediate between those observed for the parent cyclen 9 and those found for the fully substituted $\{(\mathrm{Me}) 2(\mu$-ET)-cyclen $\} 22$ analogous derivatives. This trend is in line with the residual presence of two slightly acidic NH axial groups attached to the CoIII centre in the present compound, still capable of induced base-catalysed substitution reactivity.29,36 At the same time-scale, for the parent cyclen derivative, the presence of very acidic equatorial $\mathrm{NH}$ groups, 29 induce fast polymerization reactions. 9 As found for the previously studied related systems, the absorbance changes increase significantly with increasing $\mathrm{pH}$, but can be reversed in a fast process by addition of $\mathrm{HClO} 4$ to acidic $\mathrm{pH}$. At $\mathrm{pH}>7.5$ the changes associated with the second process become very important and are related to the lack of reactivity observed with the variety of ligands studied (see the following section).

Summarising, the behaviour of the $[\mathrm{Co}\{(\mu-\mathrm{ET})$ cyclen $\}-(\mathrm{H} 2 \mathrm{O}) 2] 3+$ system has intermediate features between those of the parent cyclen9 and $\{(\mathrm{Me}) 2(\mu$-ET)cyclen $\} 22$ derivatives. The polymerisation equilibria indicated in Scheme 2 are at $\mathrm{pH}$ values higher than 7.5 (after 30 minutes at room temperature, see below) significantly displaced to the formation of a dimeric dead-end bis-hydroxo [ $(\mathrm{Co}\{(\mu-$ ET)cyclen $\}) 2(\mu-\mathrm{OH}) 2] 4+$ complex. At lower $\mathrm{pH}$ values (within the 6.0-7.0 range) the monohydroxobridged dinuclear species is prevalent on equilibration for a few minutes, and reactivity is, consequently, expected from the aqua ligands.9,22

\section{Substitution reactions on $[\mathrm{Co}\{(\mu-\mathrm{ET}) \mathrm{cyclen}\}(\mathrm{H2O}) 2] 3+$ in the $6.0-7.5 \mathrm{pH}$ range by chloride, phosphate, cytidine, thymidine, uridine, 5'-cytidinemonophosphate, 5'-thymidinemonophosphate and 5'-uridinemonophosphate}

After the knowledge of the solution nature of the equilibrated species of the $[\mathrm{Co}\{(\mu-$ ET)cyclen $\}(\mathrm{H} 2 \mathrm{O}) 2] 3+$ complex in the $6.0-7.5 \mathrm{pH}$ range, and in view of some studies carried out on this 
core in biologically relevant processes, 18,37 the reactivity at physiological $\mathrm{pH}$ of the complex was pursued. For the parent cyclen and $\{(\mathrm{Me}) 2(\mu$-ET)cyclen $\}$ complexes at these $\mathrm{pHs}, 9,22$ no reactivity with chloride had been observed, which is relevant in view of the chemistry of cis-platinum at different $\mathrm{pCl} .38-41$ For the present complex, the substitution of the aqua/hydroxo ligands at $\mathrm{pH}$ values between 6.0 and 7.5 and at $[\mathrm{Cl}-]=0.05-0.075 \mathrm{M}$ is also not observed after 24 hours at $40^{\circ} \mathrm{C}$.

Phosphate. As a follow up, the reactivity of the complex with simple inorganic phosphates was studied as a model for the substitution processes occurring with nucleotides. Furthermore, the process has a perfect spectroscopic NMR handle21,42 for the establishment of the nature of the reacting and final complexes. Monitoring the spectral changes on non-equilibrated, freshly prepared, solutions of compound $[\mathrm{Co}\{(\mu-\mathrm{ET})$-cyclen $\}(\mathrm{H} 2 \mathrm{O}) 2] 3^{+}$, with phosphate leads to a complex sequence where the fastest changes were equivalent to those observed for solutions not-containing the ligand. Thus, by using the methodology indicated in the Experimental section, 9,21,22 the time-resolved UV-Vis spectral changes occurring on pre-equilibrated (30 minutes at room temperature) samples of [Co $\{(\mu$-ET)cyclen $\}(\mathrm{H} 2 \mathrm{O}) 2] 3+$ at the relevant $\mathrm{pHs}$ were monitored instead. The changes observed (Fig. 2a) in the UV-Vis spectrum, can be fitted to a two-step reaction sequence with rather similar rate constants that were obtained as described in the Experimental section.43,44 While a definite limiting dependence, i.e. kobs $1=\operatorname{KOS} \times \mathrm{k} 1[$ phosphate $] /(1+\mathrm{KOS}[$ phosphate $])$, on the total concentration of phosphate is evident for one of the steps observed, no dependence on concentration is obtained for the other step in the sequence (Fig. 2b). Clearly the limiting first-order rate constant obtained from these plots corresponds to the coordination of a phosphate anion on a precursor outersphere encounter complex (as already been established for other phosphorous oxoanion substitution reactions).45-47 Consequently, the other reaction should correspond to a consecutive chelation, or bridging, of the ligand after its coordination. Table 1 shows the relevant kinetic data for these processes.

For the concentration dependent (k1) path, the limiting behaviour agrees with that observed for the parent cyclen complex, but is contrary to that for the $\{(\mathrm{Me}) 2(\mu$-ET)cyclen $\}$ analogue.9,22 Clearly, as found in other systems, 33 the available and well-oriented $\mathrm{NH}$ groups in the macrocyclic ligand promote such outer-sphere association complexes with the entering anion (avKOS $=120 \mathrm{M}-1$ in this case). As for the outcome of the concentration independent $(\mathrm{k} 2)$ path, 31P NMR spectroscopy of the final reaction mixtures indicated the presence of a phosphato ligand with either a $\eta 2$ or $\mu$ geometrical arrangement (20 ppm downfield from the signal of the free anion). 42 Experiments carried out with a $[\mathrm{Co}]:[\mathrm{P}]$ total $=1: 5$ ratio produced a final $[\mathrm{P}]$ total : $[\mathrm{P}] 20 \mathrm{ppm}=4.5: 0.5$, thus indicating that a simple $[(\mathrm{Co}\{(\mu-$ ET)cyclen $\}) 2(\mu-O O P O 2)(\mu-O H)] 2+$ complex is formed after the reaction (Scheme 3, top). The same arrangement has been observed for the parent unsubstituted cyclen derivative, 9 which is in line with that indicated in Scheme 2. Finally it is interesting to note, as seen both in Fig. $2 b$ and Table 1, that, although some $\mathrm{pH}$ trends might be present in the rate constants determined, these are not significant; the reactions seem to be $\mathrm{pH}$ independent in the narrow range studied (6.0-7.0). In view of the reactivity observed, completely parallel to that for the parent cyclen derivative, 9 the thermal and pressure activation parameters for this system have not been determined.

Cytidine. The study of substitution reactions on the above mentioned CoIII complex with biologically relevant ligands with nitrogen donors, i.e. nucleosides or nucleobases, was further intended (after the equilibration indicated in the previous section). No changes were observed at $\mathrm{pH} \geq 7.5$, in good agreement with the formation of the dead-end bis-hydroxobridged dimers (Scheme 2), and the reaction was only studied in the $6.0-7.0 \mathrm{pH}$ range, where the $[(\mathrm{Co}\{(\mu-\mathrm{ET}) \operatorname{cyclen}\}(\mathrm{H} 2 \mathrm{O})) 2(\mu-\mathrm{OH})] 5+$ species is prevalent in the medium. By using the standard software, 43,44 these changes were associated with a twostep sequential process. Water Presat proton NMR experiments on the reacting solutions established the nature of the two species appearing during the process. The spectrum collected after 1 hour of reaction at $40{ }^{\circ} \mathrm{C}$ at $\mathrm{pH}=6.1$ shows, apart from the intense doublet at $7.8 \mathrm{ppm}$ corresponding to the para-NH proton of the ring of the free cytidine, a signal at $7.7 \mathrm{ppm}$. After further 24 hours under the same reaction conditions, the signal at $7.7 \mathrm{ppm}$ increases its intensity and a new signal appears at 7.6 
$\mathrm{ppm}$. These data agree with the initial formation of a mono-cytidine complex $(7.7 \mathrm{ppm})$ that evolves to a bis-cytidine species (7.6 ppm) with time (Fig. S2 $\dagger$ ) in an equilibrium overall process. Fig. S3† shows the trends observed for the two pseudo-first order rate constants with the concentration of cytidine; the values derived at different pHs are shown in Table 1. From these plots it is clear that an equilibrium condition is established for both substitution reactions (as indicated by the NMR data). The equilibrium constants (10-40 M-1 for $\mathrm{K} 1$ and 50-90 M-1 for K2) indicate a definite preference for the bissubstituted $[(\mathrm{Co}\{(\mu-\mathrm{ET}) \mathrm{cyclen}\}$ (cytidine) $) 2(\mu-\mathrm{OH})] 5+$ complex. The slight acceleration (see Table 1) of the rate on increasing the basicity of the medium is in good agreement with the residual operation of a conjugate-base mechanism due to the existence of $\mathrm{NH}$ groups in the cobalt encapsulating ligand used. Given the complexity of the data only the thermal activation parameters at $\mathrm{pH}=6.5$ have been determined. For $\Delta \mathrm{H}_{*}$, the values indicate in all cases a high degree of dissociativeness, as expected for CoIII complexes when conjugate-base mechanisms might be operative. The values for the activation entropies are also positive, but less than expected for this type of activation, especially as k1 and $\mathrm{k} 2$ on rate constants are concerned. The inclusion of the outer-sphere association constants in the value used for the determination of these parameters might be responsible for the lesser degree of dissociativeness observed.

Thymidine. Initially, as for previous studies,22 thymidine (Scheme 1) was chosen due to the neutral characteristics of its nitrogen donor $(\mathrm{pKa}=9.8), 48,49$ which allows for a simplification of the system, despite its anionic nature once coordinated to the CoIII centre.33 Fig. 3a shows the typical UV-Vis spectral changes observed in the system and Fig. $3 \mathrm{~b}$ shows the trends for the pseudo-first-order rate constants obtained at different acidities for this substitution process with thymidine. While the slow step (kobs2) shows a linear dependence on the concentration of the entering ligand, the fastest step (kobs1) clearly shows a limiting behaviour22,35,50,51 on the thymidine concentration (as already found for the phosphate substitution process, see above). As in previous studies, no dependence on the $\mathrm{pH}$ is observed, and the limiting value of the fast step $(\mathrm{k} 1(\mathrm{~s}-1))$ and the slope of the dependence of the second step (k2 (M-1 s-1)) were obtained from an average of the data at the same thymidine concentrations at different $\mathrm{pHs}$. The relevant data extracted from these plots indicated are shown in Table 1.

Thus, as for cytidine, the substitution reaction of complex $[\mathrm{Co}\{(\mu-\mathrm{ET})$ cyclen $\}(\mathrm{H} 2 \mathrm{O}) 2] 3+$ with thymidine at $\mathrm{pH}$ values between 6.0 and 7.0 corresponds to a process occurring on the mono-hydroxo bridged $[(\mathrm{Co}\{(\mu-\mathrm{ET}) \operatorname{cyclen}\}(\mathrm{H} 2 \mathrm{O})) 2(\mu-\mathrm{OH})] 5+$ species prevalent in this medium (see Scheme 3 , bottom). The reaction produces the bis-substituted $[(\mathrm{Co}\{(\mu-\mathrm{ET})$ cyclen $\}$ (thymidine $)) 2(\mu-\mathrm{OH})] 3+$ species as the final complex via a clear dissociative activation mechanism for each sequential step. This is evidenced by the large values of $\Delta \mathrm{H} \ddagger$ (Table 1 ) of the same magnitude than those found for similar dissociatively activated CoIII amine complexes.52-54 Interestingly, the values determined for $\Delta \mathrm{S} \ddagger$ are practically zero, and the volumes of activation are negative for the $\mathrm{k} 1$ process and positive for the $\mathrm{k} 2$ step. This unexpected trend in the values of $\Delta \mathrm{S}_{\sharp}^{\dagger}$, and their lack of correlation with $\Delta \mathrm{V} \ddagger$, has been related to the existence of important solvent assisted hydrogen bonding interactions in the transition state of the substitution process.55-59 This is not surprising in this case, the nature of both the entering and encapsulating ligands (see Scheme 1) should be prone to hydrogen bonding interactions. In this respect, the previously reported 22 reaction of $\left[\mathrm{Co}\{(\mathrm{Me}) 2(\mu\right.$-ET)cyclen $\}(\mathrm{H} 2 \mathrm{O}) 2] 3+$ with $5^{\prime}$-TMP is a clear example of this effect in this family of substitution processes.

In contraposition with that observed for the cytidine substitution, where no acidic protons are available in the ligand, for the entry of the first thymidine nucleoside the reaction involves the limiting formation of an outer-sphere encounter precursor complex (KOS $=240 \mathrm{M}-1$, Fig. $3 \mathrm{~b}$ and Table 1), as found for other substitution reactions on CoIII amine systems, 47,60 as well as on the related $[\mathrm{Co}\{\mathrm{Me}) 2(\mu-$ $\mathrm{T})$ cyclen $\}-(\mathrm{OH})(\mathrm{H} 2 \mathrm{O})] 2+$ complex.22 The formation of this outer-sphere complex has been associated with the interaction of the proanionic $\{\mathrm{ONO}\}$ unit of the nucleoside (see Scheme 1) both with the protons of the remaining aqua ligand in the CoIII complex at this $\mathrm{pH}$ and the NH groups in the ligand.33 Effectively, for this nucleoside the value of KOS is an order of magnitude larger than for the not- 
containing NH group analogue systems studied.22 As for the entry of the second thymidine ligand, the value of the outer-sphere association equilibrium constant has definitively decreased in a way that a simple linear dependence between the value of kobs2 and [thymidine] is obtained (Fig. 3b). The decrease of the positive charge of the CoIII complex, produced by the first substitution of $\mathrm{H} 2 \mathrm{O}$ by thymidine (which involves its deprotonation to the thymidine $\{-\mathrm{H}\}$-anionic ligand) 7,33 can easily explain this fact.

The fact that the water by thymidine substitution reactions are not affected by the $\mathrm{pH}$ in the narrow range studied is somehow surprising. A compensation effect between the increasing amounts of the more labile $\mathrm{H} 2 \mathrm{O} / \mathrm{OH}-\mathrm{CoIII}$ species on decreasing the $\mathrm{pH}$, and the viability of an accelerated baseconjugated substitution on its increase, seems to result in the final outcome observed. Furthermore, the protonation ambiguity effect on putative full hydroxo outer-sphere complexes can also explain this fact for the first nucleobase entry.61

Uridine. The substitution process with a very similar uridine nucleoside (Scheme 1) was also pursued and a completely parallel behaviour with respect to the substitution by thymidine (Fig. S4†) has been observed. The slightly higher values of the rate constants can be associated with its lower steric requirements (see Scheme 3$)$. Furthermore, its higher $(\mathrm{pKa}=9.3) 62$ acidity also weakens the outersphere association of the $\{\mathrm{ONO}\}$ unit of the nucleoside, as observed from the less pronounced curvature for the k1 versus [uridine] trend (Fig. S4a†). Given the similarity obtained with the thymidine studies above, as well as the expected character of the variations observed, no further studies related to $\mathrm{pH}$ variation and activation parameters were conducted.

5'-CMP. Once the reactivity with phosphates and nucleosides was established, the substitution processes by nucleotides was pursued;9,22 the 5'-CMP nucleotide has been our first choice due to the similar anionic behaviour to phosphate anions, as well as for its non-pro-anionic nature on the nucleoside moiety. Effectively, as for the H2PO4-/HPO42- system the spectral changes indicate a twostep reactivity pattern at $40^{\circ} \mathrm{C}$ within the $6.0-7.0 \mathrm{pH}$ range, where the ligand is in the $5^{\prime}-\mathrm{CMP}-15^{\prime}$ CMP2 - forms. 63 The global fitting of these timeresolved changes 43,44 produced a series of rate constants that are concentration dependent for the two consecutive steps (Fig. S5†). 31P NMR spectroscopy indicated that an initial species is formed showing a signal at $9.4 \mathrm{ppm}$ downfield from that of the free ligand, followed by the appearance of another signal at $14.1 \mathrm{ppm}$ also downfield from that of the free ligand. Both signals coexist in the final reaction mixture and correspond to mono-dentate phosphato ligands involved in equilibrium (Fig. S6 $†$ ). The full reaction scheme for this system, parallels what has been observed for the parent [Co(cyclen)-(H2O)2]3+ compound (Scheme 4, top). 9 The fact that no induction period has been observed in the NMR experiments, and that the shift in the UV-Vis occurs to lower energies, is also an indicative of the neat formation of O-bound 5'-CMP complex. The data collected in Table 1 indicate that, in contrast to the observed for the reaction with inorganic phosphate, the reaction rate increases with $\mathrm{pH}$. The increasing presence of fully deprotonated 5'-CMP2$(\mathrm{pKa}=6.1)$ species, not so much relevant for inorganic phosphate $(\mathrm{pKa}=7.21)$, seems to be decisive. 42,63

The absence of a measurable value of KOS for the substitution by 5'-CMP, when compared to that with inorganic phosphates, is in line with an intermediate behaviour from that observed for the reactions with $[\mathrm{Co}($ cyclen $)(\mathrm{H} 2 \mathrm{O}) 2] 3+$ and those with $[\mathrm{Co}\{(\mathrm{Me}) 2(\mu-\mathrm{ET}) \mathrm{cyclen}\}(\mathrm{H} 2 \mathrm{O}) 2] 3+.9,22$ Clearly the presence of $\mathrm{NH}$ groups in the ligand structure (see Scheme 1) plays a determinant role in the outer-sphere association with the smaller H2PO4-/HPO42-, which is not possible with the more encumbered 5'CMP-/5'-CMP2- anion. Nevertheless, additional hydrogen bonding interactions with the solvent may also be a competing factor to account for the weaker interactions observed between the CoIII complex and the ligand in this case. From the data in Table 1 the values of $\mathrm{K} 1$ and $\mathrm{K} 2$ are found equivalent considering the methodological errors involved, their values are apparently also independent of the $\mathrm{pH}$ and within the $7-11 \mathrm{M}-1$ range. 
As for the thermal activation parameters shown in Table 1 for this system, it is interesting to note that, while for the first entry of 5'-CMP the direct process has all the characteristics of a dissociatively activated reaction, for the entry of the second ligand a much higher degree of associativeness is observed. The same is observed for the aquation reaction occurring on the same material, i.e. [ $(\operatorname{Co}\{(\mu-$ ET)cyclen $\left.\left.\}\left(5^{\prime}-\mathrm{CMP}\right)\right)(\mu-\mathrm{OH})-(\mathrm{Co}\{(\mu-\mathrm{ET}) \mathrm{cyclen}\}(\mathrm{H} 2 \mathrm{O}))\right] 3+$ (Scheme 4$)$. It is clear that, although a dissociatively activated substitution mechanism is expected for tetraamine CoIII complexes, especially when a conjugatebase process can be operative, 28,36 outer-sphere interactions lead to a certain degree of association which also facilitates the reaction. It is clear that the nature of the complex plays a key role in the above mentioned interactions, especially taking into account the presence of two NH groups in the macrocyclic ligand of the inert skeleton. In fact a recent report has appeared in reference to such outer-sphere interactions as responsible for deeply tuning the electronics of rather simple complexes.64

5'-TMP. The substitution reactions with the 5'-TMP nucleotide (Scheme 1) were studied to generalise the interesting substitution trends observed for the different phosphates with this CoIII complex.22 The nature of this nucleotide allows the formation of anionic $\mathrm{N}$ - and O-bound nucleotide complexes. As for the previous systems in the present report, the timeresolved UV-Vis spectral changes can be fitted to a two-step sequence with the concentration and $\mathrm{pH}$ dependence characteristics indicated in Fig. 4. 31P NMR experiments were conducted to establish the nature of the product of the two set of consecutive processes. After 30 minutes at $40^{\circ} \mathrm{C}$ and $\mathrm{pH}=6.5$ the only signal appearing in the 31P NMR corresponds to that of the free ligand (2.9 ppm), while after a further period of 10 hours a new signal at $12.6 \mathrm{ppm}$ appears, corresponding to a mono-dentate O-phosphate. The relative intensity of these 31P NMR signals indicate the entry of a single phosphate ligand per each CoIII 2 unit, thus indicating the validity of the implied reactive species indicated in Schemes 2 and 4 in this narrow $\mathrm{pH}$ range. It is thus clear that the same behaviour observed for the fully alkylated derivative is operative: 22 formation of $\left[\left(\mathrm{Co}\{(\mu-\mathrm{ET}) \operatorname{cyclen}\}\left(\mathrm{N}-5^{\prime}-\mathrm{TMP}\right)\right)(\mu-\mathrm{OH})(\mathrm{Co}\{(\mu-\mathrm{ET})-\mathrm{cyclen}\}(\mathrm{H} 2 \mathrm{O}))\right] 4+$ that evolves to the final $\left[\left(\mathrm{Co}\{(\mu-\mathrm{ET})\right.\right.$ cyclen $\left.\left.\}-\left(\mathrm{N}-5^{\prime}-\mathrm{TMP}\right)\right)(\mu-\mathrm{OH})\left(\mathrm{Co}\{(\mu-\mathrm{ET}) \operatorname{cyclen}\}\left(\mathrm{O}-5^{\prime}-\mathrm{TMP}\right)\right)\right] 2+$ species. On standing for longer periods, the final fully substituted species isomerises with the formation of $\{(\mathrm{Co}\{(\mu-$ ET)cyclen $\left.\left.\}\left(\mathrm{O}-5^{\prime}-\mathrm{TMP}\right)\right) 2(\mu-\mathrm{OH})\right\}$ units, as evidenced by a new signal on the 31P NMR spectrum appearing at $17.4 \mathrm{ppm}$ (Scheme 4, bottom right). Table 1 shows the relevant kinetic and activation parameters for the substitution processes studied.

Interestingly, the values for the entry of the first 5'-TMP ligand (N-bound) have a rather low value of $\Delta \mathrm{H}+$ and extremely negative activation entropy. It is clear that, even in this inherently dissociatively activated substitution process (CoIII $\mathrm{t} 2 \mathrm{~g} 6$ ), an important outer-sphere degree of associative activation must be present, also evidenced by the values determined for $\Delta \mathrm{V} \$$. This is in good agreement with the presence of an $\{\mathrm{ONO}\}$ unit in the ligand plus some $\mathrm{NH}$ groups in the inert skeleton of the complex.33 For the entry of the second (O-bound) 5'-TMP, this effect seems to be minimised, and a large value of $\Delta \mathrm{H} \ddagger$ is determined together with values of $\Delta \mathrm{S} \ddagger$ and $\Delta \mathrm{V} \ddagger$ close to zero.

As for the absence of $\mathrm{pH}$ dependence in the values of $\mathrm{k} 1$, previously reported data referring to proton ambiguity for these systems, 61 as well as protonation of the outer-sphere complexes, 65 can be held responsible for the facts. 22 Nevertheless, taking into account the potential actuation of conjugatebase mechanisms, as well as the very narrow range of $\mathrm{pH}$ used in the study $(6.2-7.0)$, the above assumptions are highly speculative (see Fig. 4).

5'-UMP. The effect of the substitution of uridine for thymidine on the corresponding nucleotides was also studied. Fig. S7 $\uparrow$ shows the trend observed on [5'-UMP] of the two derived values of kobs at $\mathrm{pH}=$ 6.5. As for 5'-TMP the nature of the species being formed after each one of the sequential steps was assessed by $31 \mathrm{P}$ and Presat $1 \mathrm{H}$ NMR experiments (Fig. S $8 \dagger$ ). After a period of $1 \mathrm{~h}$ at $40^{\circ} \mathrm{C}$ and $\mathrm{pH}=6.8$ a signal appears at $12.4 \mathrm{ppm}$ in the 31P NMR spectrum, indicating the monodentate O-5'-UMP coordination to the cobalt centre. The parallel resat $1 \mathrm{H}$ NMR experiment indicates the presence of two doublets (7.8 and $7.9 \mathrm{ppm}$ ), the more intense at $7.9 \mathrm{ppm}$ is assigned to the mono-N-5'-UMP. The signal of the 31P NMR spectrum indicates that the proton signal at $7.8 \mathrm{ppm}$ must then correspond to a mono- 
$346 \mathrm{~N}$-mono-O species as already established for the 5'-TMP derivatives. The rate constants derived from

347 the experiments are practically equivalent to that obtained for the 5'-TMP, indicating a similar nature of

348 the reaction. Nevertheless the corresponding value for KOS is much lower than for the thymidine

349 derivative, in line with the observed for the reaction with the parent nucleosides. Given the complex

350 nature of the secondary reactions observed, no $\mathrm{pH}$, temperature or pressure dependence has been

351 pursued for this system.

\section{Comparison within the cyclen, $\{(\mu-E T) c y c l e n\}$ and $\{(\mathrm{Me}) 2(\mu-\mathrm{ET}) \mathrm{cyclen}\}$ series of complexes}

354 In Scheme 5 a comparison of the structures of the series of CoIII aqua complexes with cyclen derivatives is indicated, as well as the final thermodynamically equilibrated form existing in solution at pHs close to the physiological pH.9,22 Successive substitution on the NH groups of the cyclen ligand produces a significant decrease in the relevance of the dimerization processes under biologically significant conditions; which is related to the expected tuning on conjugatebase pathways dominant for the cyclen derivatives, 29 relevant for the simple cross-bridged derivate, and irrelevant for the complexes of the fully alkylated derivative. 22 These trends indicate a thermodynamic preference of the dimeric $\mu$ -

361 OH species.9

362 A further very interesting tuning found for the series of studies, relates to differences in hydrogen 363 bonding interactions due to the presence of NH groups in the ligand. While for the fully alkylated 364 compound hydrogen bonding interactions with thymidine seems to be solely taking place via 365 interactions with the hydroxo ligand on the monomeric CoIII centre, for the cross bridged ligand 366 compound here reported, the involvement of the axial NH group increases by an order of magnitude the stability of such an interaction (Scheme 6, left). This is especially important considering that the extreme dissociative substitution occurring on conjugate-base pathways is not too relevant for this complex (see 369 above), thus allowing for an unexpected association.

370 Precisely this outer-sphere association is selective, and the formation of N-bound thymidine for the 5'371 TMP nucleotide can be observed despite the phosphate-bound derivative being thermodynamically 372 preferred as shown in Scheme 4. Moreover, a possible outer-sphere pairing interaction can be also held 373 responsible for the unobserved bis-N-bound thymidine derivative, as indicated in Scheme 6 (right). 
377 The substitution reactivity of the $[\mathrm{Co}\{(\mu-\mathrm{ET}) \operatorname{cyclen}\}(\mathrm{H} 2 \mathrm{O}) 2] 3+$ complex cation at $\mathrm{pH}$ close to neutrality 378 is dominated by the formation of the dead-end bis-hydroxobridged $[(\mathrm{Co}\{(\mu-\mathrm{ET})$-cyclen $\}) 2(\mu-\mathrm{OH}) 2] 4+$

379 complexes at $\mathrm{pH}>7.5$, which parallels what has been observed for the parent cyclen derivative and that 380 of the fully alkylated $[(\mathrm{Co}\{(\mathrm{Me}) 2(\mu-\mathrm{ET}) \mathrm{cyclen}\}) 2(\mu-\mathrm{OH}) 2] 4+$. At $\mathrm{Ph}$ values within the $6.0-7.0$ range 381 substitution reactivity occurs solely on the mono-hydroxobridged [ $(\mathrm{Co}\{(\mu$-ET)cyclen $\}-(\mathrm{H} 2 \mathrm{O})) 2(\mu-$ $382 \mathrm{OH})] 5+$ species, as observed for the cyclen analogous system, but differing from the fully alkylated 383 derivative where this species is only residual. It is clear that the presence of $\mathrm{NH}$ groups in the axial 384 coordination positions of the complex (Scheme 1) dominates this reactivity, whereas that of the highly 385 acidic $\mathrm{NH}$ in the equatorial positions of the [Co(cyclen)-(H2O)2]3+ complex is only responsible for the 386 readiness and equilibrium position of the mono-hydroxobridged species formation reaction.

387 The kinetico-mechanistic studies conducted on the substitution of the aqua/hydroxo ligands of this 388 dinuclear species with biologically significant ligands are indicative of an important role of outer-sphere 389 complexation. The appearance of limiting kinetics is rather general, and with values of KOS that are in 390 line with the intervention of both the leaving aqua ligands and the residual $\mathrm{NH}$ groups in the 391 encapsulating $\{(\mu-\mathrm{ET})$-cyclen $\}$ ligand (Scheme 6$)$. The formation of hydrogenbonded encounter complexes results in the preferential formation of O- or N-bonded nucleotides depending on the structure of the base moiety of the ligand. Furthermore, as observed for the reaction with mononuclear $[\mathrm{Co}\{(\mathrm{Me}) 2(\mu-\mathrm{ET})$ cyclen $\}(\mathrm{H} 2 \mathrm{O})-(\mathrm{OH})] 2+$, the selective entry of the different donor bonded nucleotides can also be hampered by the hydrogenbonding interaction with the dangling moiety of the coordinated ligand. As expected, the processes occur at a faster rate than for the fully alkylated encapsulating ligand derivative, given the still available base-catalysing $\mathrm{NH}$ groups in $\{(\mu$-ET $)$ cyclen $\}$. 


\section{Compounds and procedures}

402 The cobalt $[\mathrm{Co}\{(\mu-\mathrm{ET}) \mathrm{cyclen}\}(\mathrm{H} 2 \mathrm{O}) 2](\mathrm{CF} 3 \mathrm{SO} 3) 3$ complex has been prepared directly by crystallisation of the already described $[\mathrm{Co}\{(\mu$-ET)cyclen $\}(\mathrm{CF} 3 \mathrm{SO} 3) 2](\mathrm{CF} 3 \mathrm{SO} 3)$ in a minimum amount of slightly acidic (HCF3SO3) water.18 The complex was characterised by its elemental analyses (Calc., found $\%)$ for [Co $\{(\mu$-ET)cyclen $\}(\mathrm{H} 2 \mathrm{O}) 2](\mathrm{CF} 3 \mathrm{SO} 3) 3 \cdot 1.5 \mathrm{H} 2 \mathrm{O}$ : $\mathrm{C}: 20.3,20.0 ; \mathrm{N}: 7.3,7.2 ; \mathrm{H}: 3.8,3.7$; S: 12.5, 12.6. 13C NMR $(57.6,62.8,63.2 \mathrm{ppm})$ and UV-Vis spectra $(\lambda \max =360 \mathrm{~nm}(110 \mathrm{M}-1 \mathrm{~cm}-1)$; $\lambda \max =490 \mathrm{~nm}(180 \mathrm{M}-1 \mathrm{~cm}-1))$. XRD quality crystals were also obtained; Fig. 1 shows the molecular drawing of the complex cation and Table 2 the corresponding crystal data and structure refinement. The nucleosides and nucleotides used were commercially available and were used as received.

MES and HEPES solutions were prepared to a $0.4 \mathrm{M}$ concentration at $\mathrm{I}=1.0(\mathrm{NaClO} 4)$ by weighing the desired amounts of the commercially available reactants. Final $\mathrm{pH}$ was adjusted with suitable $\mathrm{HClO} 4$ or $\mathrm{NaOH}$ solutions. 32 These stock solutions were used as the solvent for all the ligand solutions used in the study. As a standard procedure the $\mathrm{pH}$ of the samples at the desired temperature was monitored before and after randomly selected experiments; no significant differences were obtained in any case and the procedure was thus considered valid under the conditions used.

13C and 31P NMR spectroscopy were carried out on Bruker 400-Crio instrument in $\mathrm{H} 2 \mathrm{O}$ adjusted at the desired $\mathrm{pH}$, and with a $\mathrm{D} 2 \mathrm{O}$ inset containing the corresponding reference, at the Unitat d'RMN from the Centres Científics i Tecnològics de la Universitat de Barcelona (CCiTUB). The spectra were referenced externally to NaTMPS (13C) and H3PO4 (31P). 1H NMR spectra from the same aqueous solutions were recorded using a water Presat experiment on the same instrument. UV-Vis spectra were recorded using either a Cary 50 or a HP8453 instrument equipped with thermostated multicell transports. For the reactions carried out at varying pressure the already described pillbox cell and pressurising systems6669 were used connected to a J\&M TIDAS instrument. pH measurements were conducted on a Crison instrument using either fast response or microsample glass combined electrodes. Time-resolved UV-Vis spectra were recorded with the same instruments and exported to the relevant software packages indicated below.

pKa determination was carried out by UV-Vis spectroscopy titration on $1 \times 10-3 \mathrm{M}$ solutions of the cobalt complex, taken to $0.01 \mathrm{M} \mathrm{HClO} 4$, by adding small aliquots of $0.1 \mathrm{M} \mathrm{NaOH}$. Electronic spectra (Fig. S8 $\dagger$ ) were recorded by using a Helma 661.202-UV All Quartz Immersion Probe connected to a Cary 50 instrument with optical fibres. The pKa determination was carried out using the standard Specfit or ReactLab Equilibrium software.43,44

\section{Kinetics}

Solutions of the different ligands involved in the kinetic runs were prepared in the corresponding $0.4 \mathrm{M}$ buffer solutions at $\mathrm{I}=1.0$ described above. The solutions of the metal complex were prepared at much higher concentrations (20-30 fold) in water; thus an effective acidic $\mathrm{pH}$ was achieved, which prevented its polymerisation processes. Small aliquots of this stock solution were added to achieve the final conditions of the runs $([\mathrm{CoIII}]=(2-7) \times 10-4 \mathrm{M}$, [ligand $]=0.01-0.1 \mathrm{M})$. For all the substitution processes pseudo-first order flooding conditions were used.

All the time-resolved experiments (by $\mathrm{pH}$, and NMR or UV-Vis spectral monitoring) were conducted following three types of setups. (i) For non-buffered medium the desired aliquot of the stock CoIII complex solution was added to a solution at a chosen acidity; $\mathrm{pH}$ was immediately registered and further UV-Vis, NMR and pH changes were monitored. (ii) For experiments in buffered media the desired 
444 aliquot of the stock CoIII complex solution was added to the chosen $0.4 \mathrm{M}$ buffer solution; $\mathrm{pH}$ was 445 registered and further UV-Vis, NMR and $\mathrm{pH}$ changes were monitored. (iii) For experiments, requiring a 446 preequilibration process, the desired aliquot of the stock CoIII complex solution was added to the 447 chosen $0.4 \mathrm{M}$ buffer solution without reactants; $\mathrm{pH}$ was registered and UV-Vis monitoring was carried 448 out. When the spectral changes associated with the equilibration process were completed a solution of 449 the desired ligand in the chosen $0.4 \mathrm{M}$ buffer was added to the final desired concentration; $\mathrm{pH}$ was 450 registered and further UV-Vis, NMR and/or $\mathrm{pH}$ changes were monitored.

All data were collected as full $(300-750 \mathrm{~nm})$ spectra and treated with the standard Specfit or ReactLab Kinetics software; 43,44 observed rate constants were obtained from the full changes of the spectra or alternatively at the wavelength where a maximum change was observed. The changes were fitted to the relevant $\mathrm{A} \rightarrow \mathrm{B}$ single exponential equation when first or pseudo-first order conditions applied; for consecutive reactions with the same characteristics, an $\mathrm{A} \rightarrow \mathrm{B} \rightarrow \mathrm{C}$ two exponential sequence was fitted. Table S1 $\uparrow$ shows all the values obtained for kobs as a function of the different compounds and variables studied.

\section{X-ray diffraction analyses}

460 A red prism-like specimen of $\mathrm{C} 13 \mathrm{H} 26 \mathrm{CoF} 9 \mathrm{~N} 4 \mathrm{O} 12 \mathrm{~S} 3$, with approximate dimensions $0.299 \times 0.127 \times$ $4610.107 \mathrm{~mm}$, was used for the X-ray crystallographic analysis. The X-ray intensity data were collected on a D8 Venture system equipped with a multilayer monochromator and a Mo microfocus $(\lambda=0.71073 \AA)$.

The frames were integrated with the Bruker SAINT software package using a narrow-frame algorithm. The integration of the data using a monoclinic unit cell yielded a total of 32892 reflections to a maximum $\theta$ angle of $26.40^{\circ}(0.80 \AA$ resolution), of which 5568 were independent (average redundancy 5.907, completeness $=99.6 \%$, Rint $=4.65 \%$, Rsig $=3.17 \%)$ and $5408(97.13 \%)$ were greater than $2 \sigma(\mathrm{F} 2)$. The final cell constants $\mathrm{a}=9.0812(4) \AA, \mathrm{b}=22.5814(13) \AA, \mathrm{c}=13.3340(7) \AA, \beta=95.368(2)^{\circ}$, volume $=2722.4(2) \AA 3$ are based upon the refinement of the XYZ-centroids of reflections above $20 \sigma(I)$. Data were corrected for absorption effects using the multi-scan method (SADABS). The calculated minimum and maximum transmission coefficients (based on crystal size) are 0.6885 and 0.7454 .

The structure was solved using the Bruker SHELXTL software package, and refined using SHELXL,70 using the space group P121/n1, with $\mathrm{Z}=4$ for the formula unit, C13H26CoF9N4O12S3. The final anisotropic full-matrix leastsquares refinement on $F 2$ with 382 variables converged at $R 1=7.27 \%$, for the observed data and $\mathrm{wR} 2=16.31 \%$ for all data. The goodness-of-fit was 1.068 . The largest peak in the final difference electron density synthesis was $1.812 \mathrm{e} \AA-3$ and the largest hole was $-1.239 \mathrm{e} \AA-3$ with an RMS deviation of 0.116 e $\AA-3$. On the basis of the final model, the calculated density was $1.851 \mathrm{~g}$ $\mathrm{cm}^{-3}$ and $\mathrm{F}(000), 1544 \mathrm{e}^{-}$. 


\section{ACKNOWLEDGEMENTS}

480

481 Financial support from the Spanish Ministerio de Economía y Competitividad (project CTQ2012-37821-

482 C02-01) is acknowledged. MV also acknowledges a FI-DGR grant from the Generalitat de Catalunya. 
1 K. Gloe, in Macrocyclic chemistry: current trends and future perspectives, Springer, Dordrecht, 2005.

4882 J. A. Cowan, in Inorganic Biochemistry. An Introduction, Wiley-VCH, 2nd edn, 1997. M. Albrecht, G. Rodríguez, J. Schoenmaker and G. van Koten, Org. Lett., 2000, 2, 3461-3464. S. V. Wegner and J. P. Spatz, Angew. Chem., Int. Ed., 2013, 52, 7593-7596. 41, 12329-12345.

495

496

497

498

N. Busto, M. Martínez-Alonso, J. M. Leal, A. M. Rodríguez, F. Domínguez, M. I. Acuña, G. Espino and B. García, Organometallics, 2014, 34, 319-327.

500 V. Pierroz, T. Joshi, A. Leonidova, C. Mari, J. Schur, I. Ott, L. Spiccia, S. Ferrari and G. Gasser, J. Am. Chem. Soc., 2012, 134, 20376-20387.

M. G. Basallote, M. Martínez and M. Vázquez, Dalton Trans., 2014, 43, 11048-11058.

C. M. Clavel, E. Paunescu, P. Nowak-Sliwinska and P. J. Dyson, Chem. Sci., 2014, 5, $1097-$ 1101

P. C. A. Bruijnincx and P. J. Sadler, Curr. Opin. Chem. Biol., 2008, 12, 197-206.

A. W. Han and P. J. Dyson, Eur. J. Inorg. Chem., 2006, 4003-4018.

H. K. Liu, S. J. Berners-Price, F. Wang, J. A. Parkinson, J. Xu, J. Bella and P. J. Sadler, Angew. Chem., Int. Ed., 2006, 45, 8153-8156.

C. Scolaro, A. Bergamo, L. Brescacin, R. Delfino, M. Cocchietto, G. Laurenczy, T. J. Geldbach, G. Sava and P. J. Dyson, J. Med. Chem., 2005, 48, 4161-4171. Fabbiani, J. E. Davidson, A. Dawson, R. E. Aird, D. I. Jodrell and P. J. Sadler, J. Med. Chem., 2006, 49, 6858-6868.

8 J. Y. C. Chang, G. L. Lu, R. J. Stevenson, P. J. Brothers, G. R. Clark, K. J. Botting, D. M. Ferry, M. Tercel, W. R. Wilson, W. A. Denny and D. C. Ware, Inorg. Chem., 2013, 52, 7688-7698.

9 T. W. Failes, C. Cullinane, C. I. Diakos, N. Yamamoto, J. G. Lyons and T. W. Hamblet, Chem. - Eur. J., 2007, 13, 2974-2982.

52022 M. Martínez and M. Vázquez, Inorg. Chem., 2015, 54, 4972-4980. 

Freeman, A. N. Cain, J. G. Le, S. J. Archibald, S. I. Khan, B. L. Tekwani and M. O. F. Khan, Bioorg. Med. Chem., 2014, 22, 3239-3244. 40.

W. Niu, E. Wong, G. Weisman, Y. Peng, C. Anderson, L. Zakharov, J. Golen and A. Rheingold, Eur. J. Inorg. Chem., 2004, 3310-3315.

M. L. Tobe, in Advances in Inorganic and Bioinorganic Mechanisms, Academic Press, London, 1983, ch. 2, pp. 1-94.

M. L. Tobe and J. Burgess, in Inorganic Reaction Mechanisms, Longman, 1999.

M. M. DeMaine and J. B. Hunt, Inorg. Chem., 1971, 10, 2106-2113. Biochemistry, 1966, 5, 467-477. Ware, Dalton Trans., 2010, 39, 11535-11550.

R. G. Wilkins, in Kinetics and Mechanisms of Reactions of Transition Metal Complexes, VCH, 1991.

55041 H. Hohmann, B. Hellquist and R. van Eldik, Inorg. Chim. Acta, 1991, 188, 25-32. Associates, Marlborough, MA, USA, 2005. 2009. 1983, ch. 2, pp. 1-94.

T. Zhang, X. Zhu and R. Prabhakar, Organometallics, 2014, 33, 1925-1935. 82.

N. de Barrios, G. González, A. Grandas, M. Martínez and V. Moreno, Inorg. React. Mech., 1999, 1, 205-218.

J. M. Coronas, R. Vicente and M. Ferrer, Inorg. Chim. Acta, 1981, 49, 259. J. Vinaixa and M. Ferrer, J. Chem. Educ., 1983, 60, 155-166. 
55847 M. Martínez and M. Ferrer, Transition Met. Chem., 1984, 9, 395-397.

55948 C. Thibaudeau, J. Plavec and J. Chattopadhyaya, J. Org. Chem., 1996, 61, 266-286.

56049 M. E. Sosa and M. L. Tobe, J. Chem. Soc., Dalton Trans., 1985, 475-477.

$56150 \quad$ J. H. Espenson, in Chemical Kinetics and Reaction Mechanisms, McGraw-Hill, 1981.

56251 A. G. Lappin, in Redox Mechanisms in Inorganic Chemistry, Ellis Horwood, 1994.

56352 G. González, B. Moullet, M. Martínez and A. E. Merbach, Inorg. Chem., 1994, 33, 2330-2333.

56453 G. González, M. Martínez and E. Rodríguez, J. Chem. Soc., Dalton Trans., 1995, 891-892.

$56554 \quad$ F. Benzo, P. V. Bernhardt, G. González, M. Martínez and B. Sienra, J. Chem. Soc., Dalton 566 Trans., 1999, 3973-3979.

56755 A. Macchioni, Eur. J. Inorg. Chem., 2003, 195-205.

56856 A. Macchioni, Chem. Rev., 2005, 105, 2039-2074.

56957 M. Martínez, M. A. Pitarque and R. van Eldik, J. Chem. Soc., Dalton Trans., 1996, 2665-2671.

$57058 \quad$ P. V. Bernhardt, F. Bozoglián, B. P. Macpherson, M. Martínez, A. E. Merbach, G. González and 571 B. Sienra, Inorg. Chem., 2004, 43, 7187-7195.

$57259 \quad$ P. V. Bernhardt, F. Bozoglián, B. P. Macpherson, M. Martínez, G. González and B. Sienra, Eur. $573 \quad$ J. Inorg. Chem., 2003, 2512-2518.

57460 G. González, M. Martínez and E. Rodríguez, Eur. J. Inorg. Chem., 2000, 1333-1338.

57561 R. B. Jordan, in Reaction mechanisms of inorganic and organometallic systems, Oxford $576 \quad$ University Press, 2007.

57762 I. Luyten, K. W. Pankiewicz, K. A. Watanabe and J. Chattopadhyaya, J. Org. Chem., 1998, 63, $578 \quad 1033-1040$.

57963 P. A. Levene and H. S. Simms, J. Biol. Chem., 1925, 65, 519-534.

58064 M. L. Souza, E. E. Castellano, J. Telser and D. W. Franco, Inorg. Chem., 2015, 54, 2067-2080.

58165 M. Ferrer, M. Martínez and M. A. Pitarque, J. Chem. Soc., Dalton Trans., 1990, 1629-1633.

58266 R. van Eldik, in Inorganic High Pressure Chemistry, ed. R. van Eldik, Elsevier, 1986, pp. 1-68.

58367 J. Garcia-Amorós, M. Martínez, H. Finkelman and D. Velasco, J. Phys. Chem. B, 2010, 114, $584 \quad 1287-1293$.

58568 B. P. Macpherson, B. M. Alzoubi, P. V. Bernhardt, M. Martínez, P. Tregloan and R. van Eldik, 586 Dalton Trans., 2005, 1459-1467.

58769 I. Favier, M. Gómez, J. Granell, M. Martínez, M. Font-Bardía and X. Solans, Dalton Trans., $588 \quad 2005,123-132$.

58970 G. M. Sheldrick, Acta Crystallogr., Sect. A: Fundam. Crystallogr., 2008, 64, 112-122. 590 
593 Figure 1 Drawing of the $[\mathrm{Co}\{(\mu-\mathrm{ET}) \operatorname{cyclen}\}(\mathrm{H} 2 \mathrm{O}) 2] 3+$ cation prepared in this work (hydrogen atoms 594 have been omitted for clarity). Relevant distances $(\AA)$ and angles $\left(^{\circ}\right)$ are: $\operatorname{Co}(1)-\mathrm{N}(1)=1.95 ; \operatorname{Co}(1)-$ $595 \mathrm{~N}(2)=1.90 ; \mathrm{Co}(1)-\mathrm{N}(3)=1.89 ; \mathrm{Co}(1)-\mathrm{N}(4)=1.96 ; \mathrm{Co}(1)-\mathrm{O}(1)=2.06 ; \mathrm{Co}(1)-\mathrm{O}(2)=1.90 ; \mathrm{N}(1)-$

598 Figure 2. (a) Changes in the electronic spectrum of a solution of $[\mathrm{Co}\{(\mu-\mathrm{ET}) \operatorname{cyclen}\}(\mathrm{H} 2 \mathrm{O}) 2] 3+$ 599 complex $(5 \times 10-4 \mathrm{M})$ in buffered aqueous solution at $\mathrm{Ph}=7.0$ of inorganic phosphate $0.01 \mathrm{M}\left(40{ }^{\circ} \mathrm{C}\right.$, 600 HEPES, $\mathrm{I}=1.0(\mathrm{NaClO} 4))$. (b) Plot of the values of the dependence of kobs on [phosphate] at different $601 \mathrm{pHs}$ at $40{ }^{\circ} \mathrm{C}(\boldsymbol{\Delta}, \mathrm{pH}=6.0 ; \mathbf{m}, \mathrm{pH}=6.5 ; \bullet, \mathrm{pH}=7.0 ; 0.4 \mathrm{M}$ MES/HEPES, I = $1.0(\mathrm{NaClO} 4))$. 602

603 Figure 3 a) Changes with time of the electronic spectrum of a $5 \times 10-4 \mathrm{M}$ solution of complex $[\mathrm{Co}\{(\mu$ $604 \mathrm{ET})$ cyclen $\}(\mathrm{H} 2 \mathrm{O}) 2] 3+$ with thymidine $0.04 \mathrm{M}$ at $\mathrm{pH}=7.0\left(\mathrm{HEPES} 0.4 \mathrm{M}, 40{ }^{\circ} \mathrm{C}, \mathrm{I}=1.0(\mathrm{NaClO} 4)\right.$ ). (b) 605 Plot of the values of the dependence of kobs on [thymidine] at different $\mathrm{pHs}$ at $40{ }^{\circ} \mathrm{C}(\boldsymbol{\Lambda}, \mathrm{pH}=6.0$; $\boldsymbol{\square}$, $606 \mathrm{pH}=6.5 ; \bullet, \mathrm{pH}=7.0 ; 0.4 \mathrm{M}$ HEPES, $\mathrm{I}=1.0(\mathrm{NaClO} 4))$.

607

608 Fig. 4 Plot of the values of the dependence of kobs on [5'-TMP-/5'-TMP2-] at different pHs at $40{ }^{\circ} \mathrm{C}$ 609 $(\boldsymbol{\Lambda}, \mathrm{pH}=6.2 ; \mathbf{\square}, \mathrm{pH}=6.5 ; \bullet, \mathrm{pH}=6.8 ; \bullet, \mathrm{pH}=7.0 ; 0.4 \mathrm{M}$ MES/HEPES, $\mathrm{I}=1.0(\mathrm{NaClO} 4))$. 


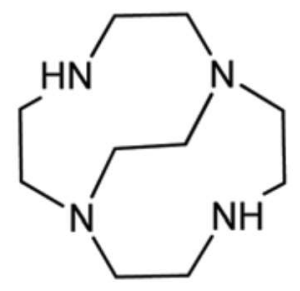

$\{(\mu-E T) c y c l e n\}$

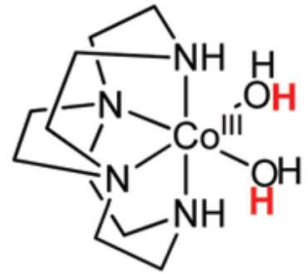

$\left[\mathrm{Co}\{(\mu-\mathrm{ET}) \text { cyclen }\}\left(\mathrm{H}_{2} \mathrm{O}\right)_{2}\right]^{3+}$<smiles>Nc1ccn([C@@H]2O[C@H](O)[C@@H](O)[C@H]2O)c(=O)n1</smiles>

cytidine<smiles>Cc1cn([C@H]2C[C@H](O)[C@@H](CO)O2)c(=O)[nH]c1=O</smiles>

thymidine<smiles>O=c1ccn([C@@H]2O[C@H](CO)[C@@H](O)[C@H]2O)c(=O)[nH]1</smiles>

uridine<smiles>Nc1ccn([C@@H]2O[C@H](COP(=O)(O)O)[C@@H](O)[C@H]2O)c(=O)n1</smiles>

5'-CMP<smiles>N[C@@H]1C[C@H](O)[C@@H](COP(=O)(O)O)O1</smiles>

5'-TMP<smiles>N[C@H]1O[C@H](O)[C@@H](COP(=O)(O)O)O1</smiles>

5'-UMP

615 


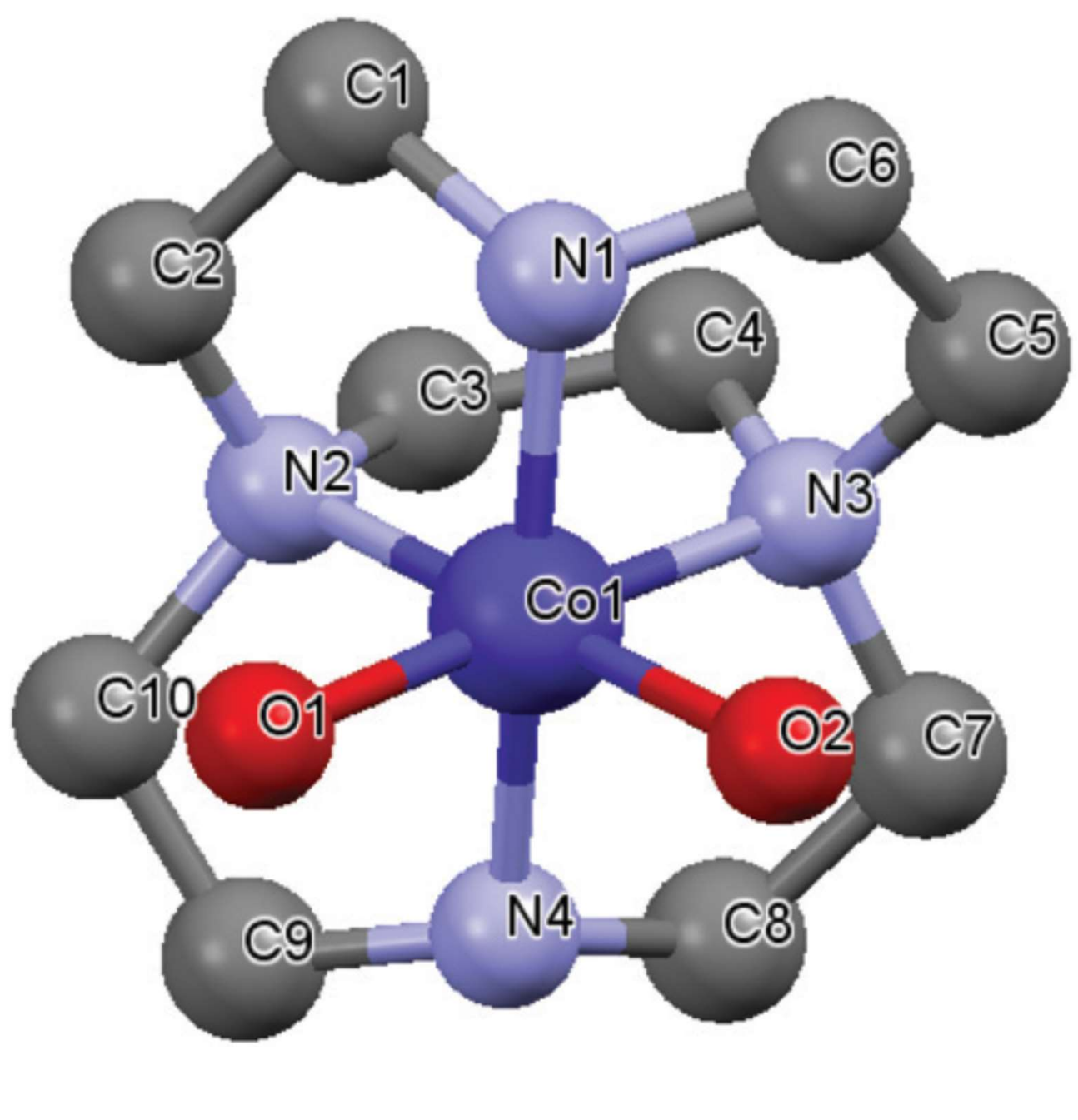



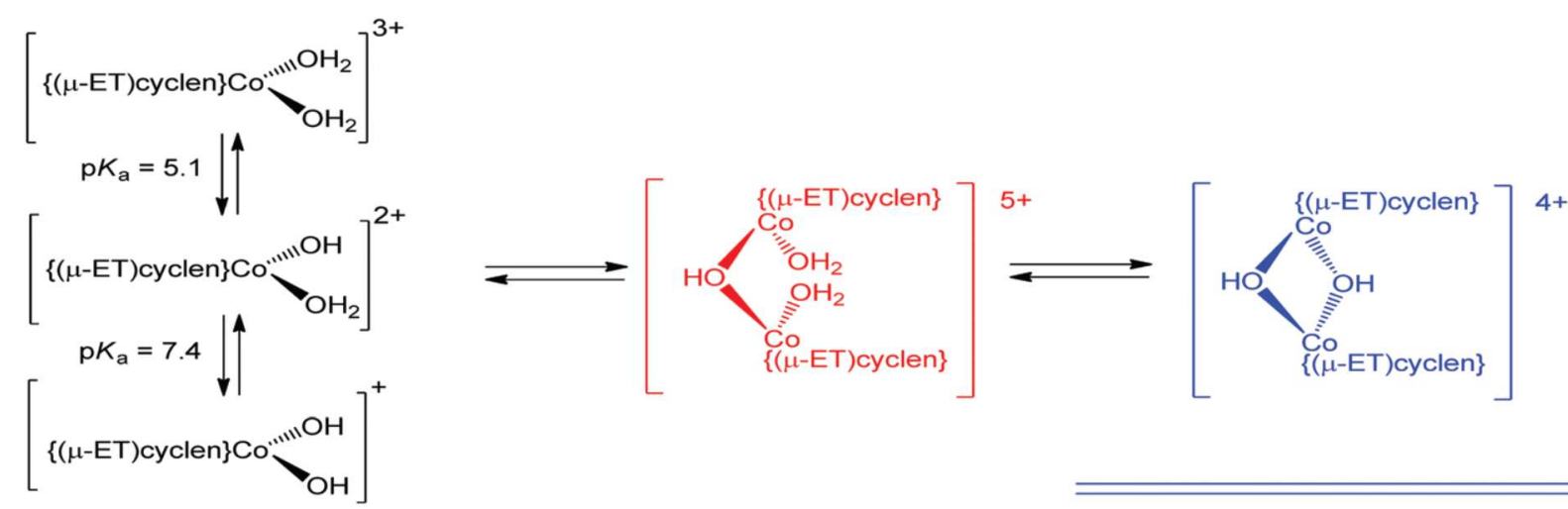

625

$\mathrm{pH}>7.5$ 
a)

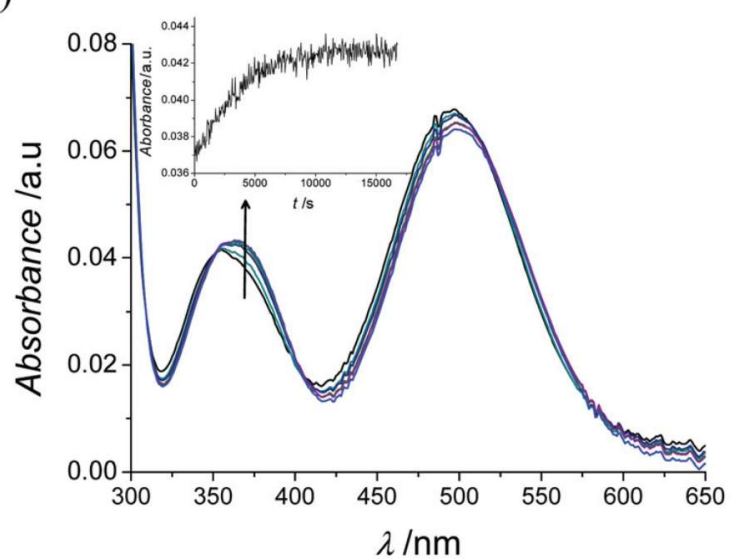

FIGURE 2

b)

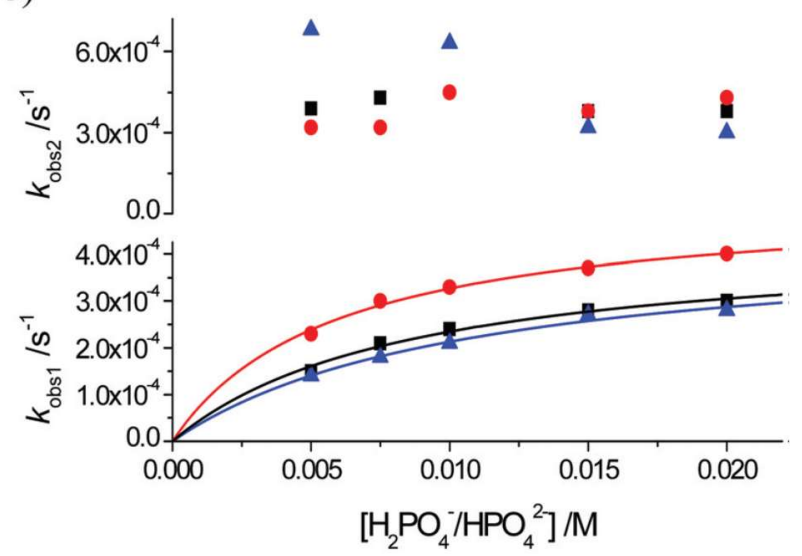




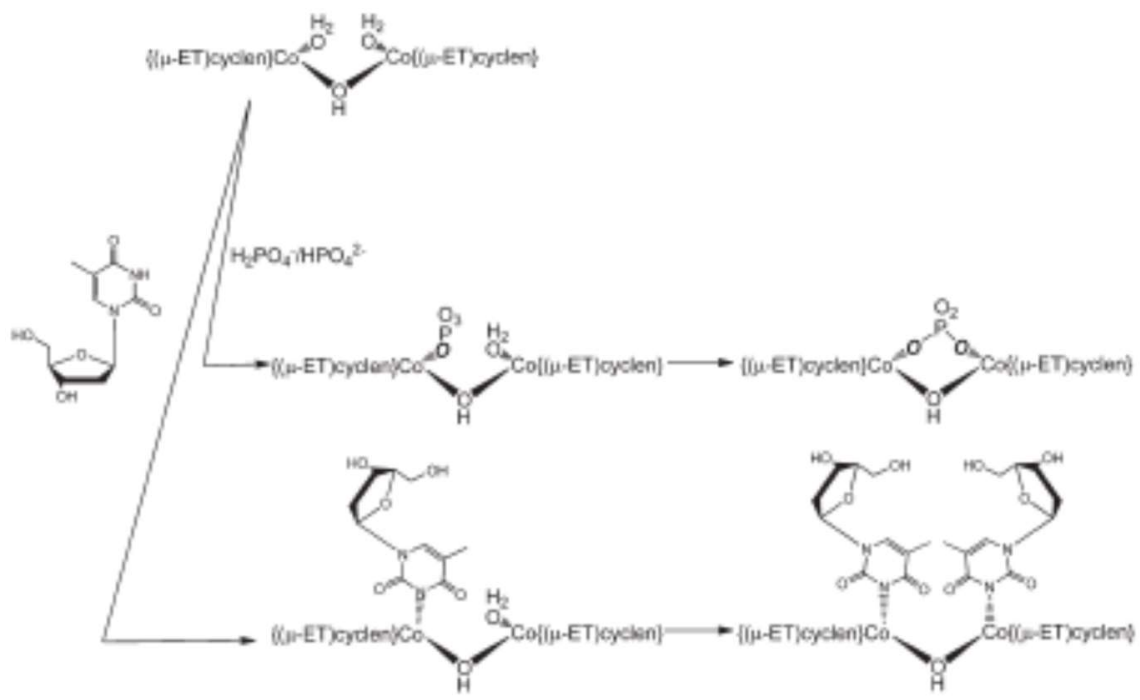


FIGURE 3

a)

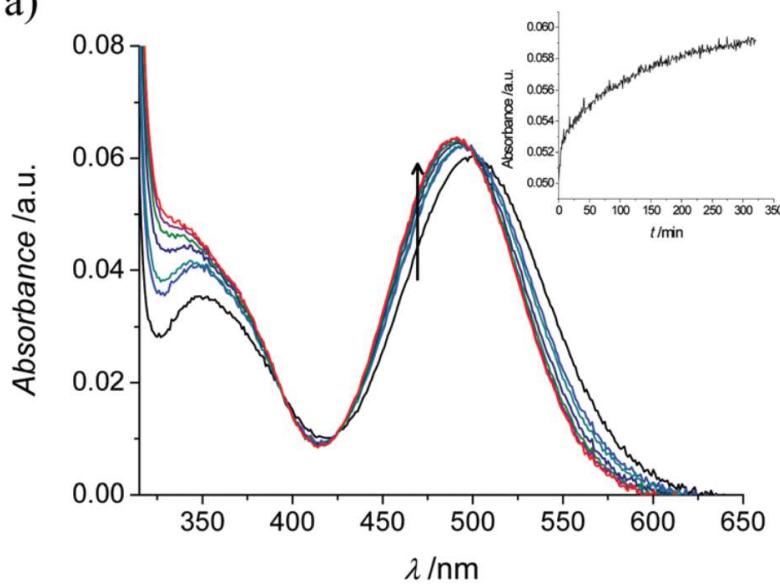

b)

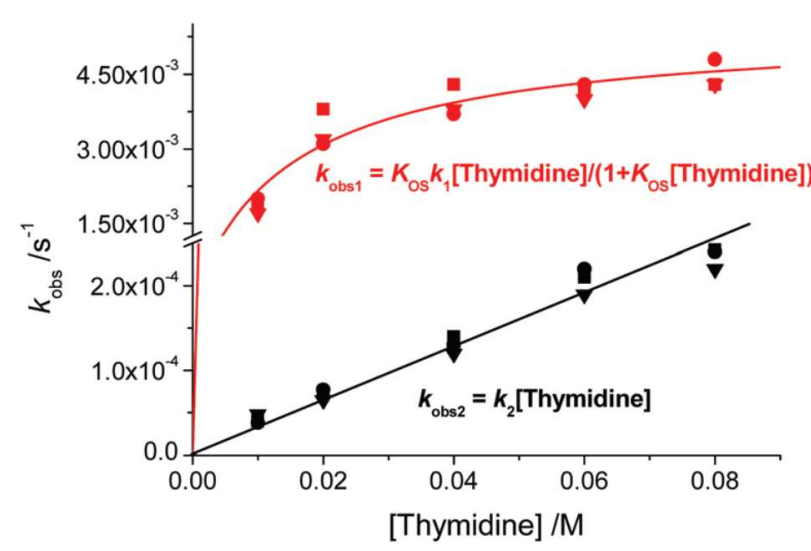



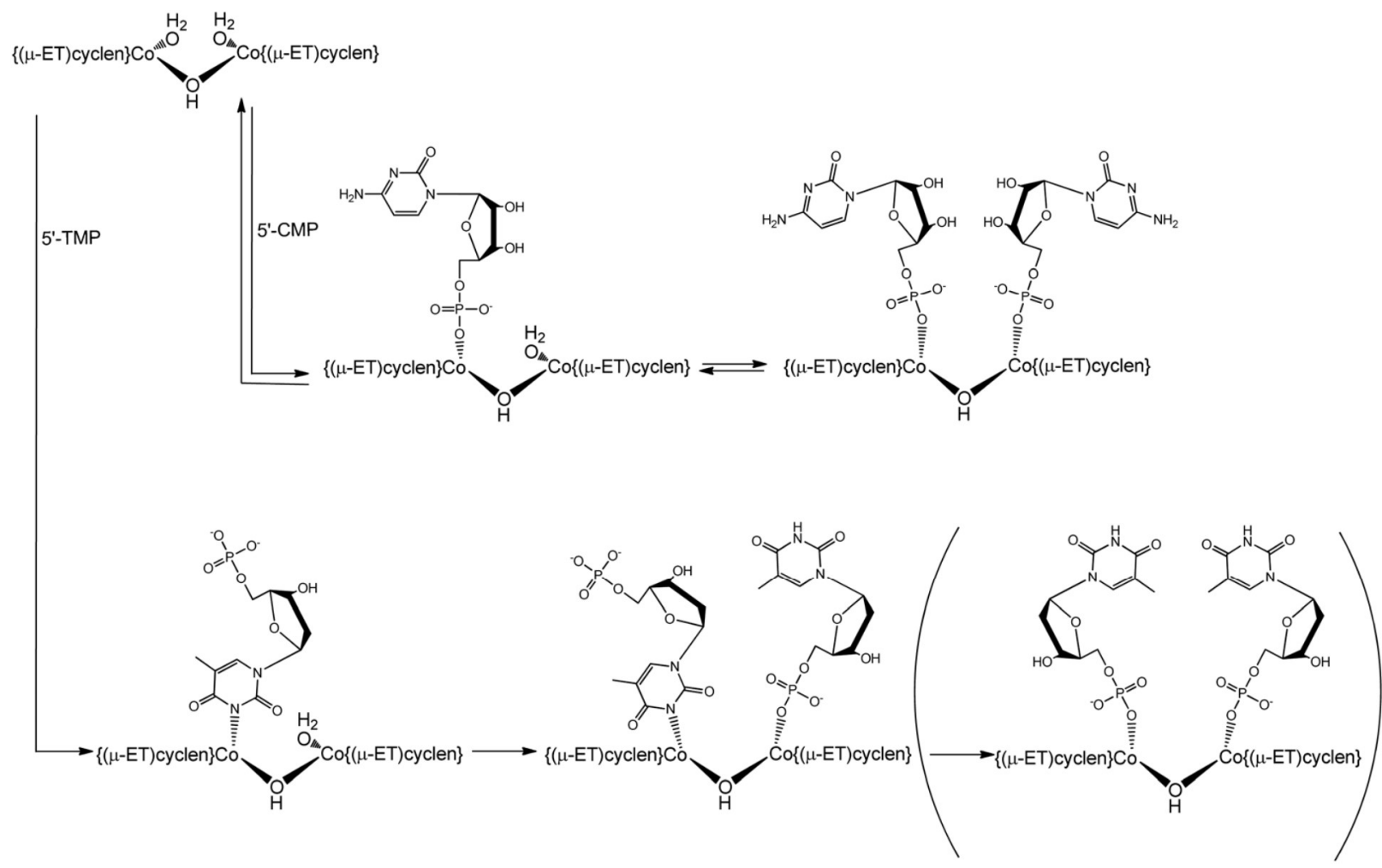


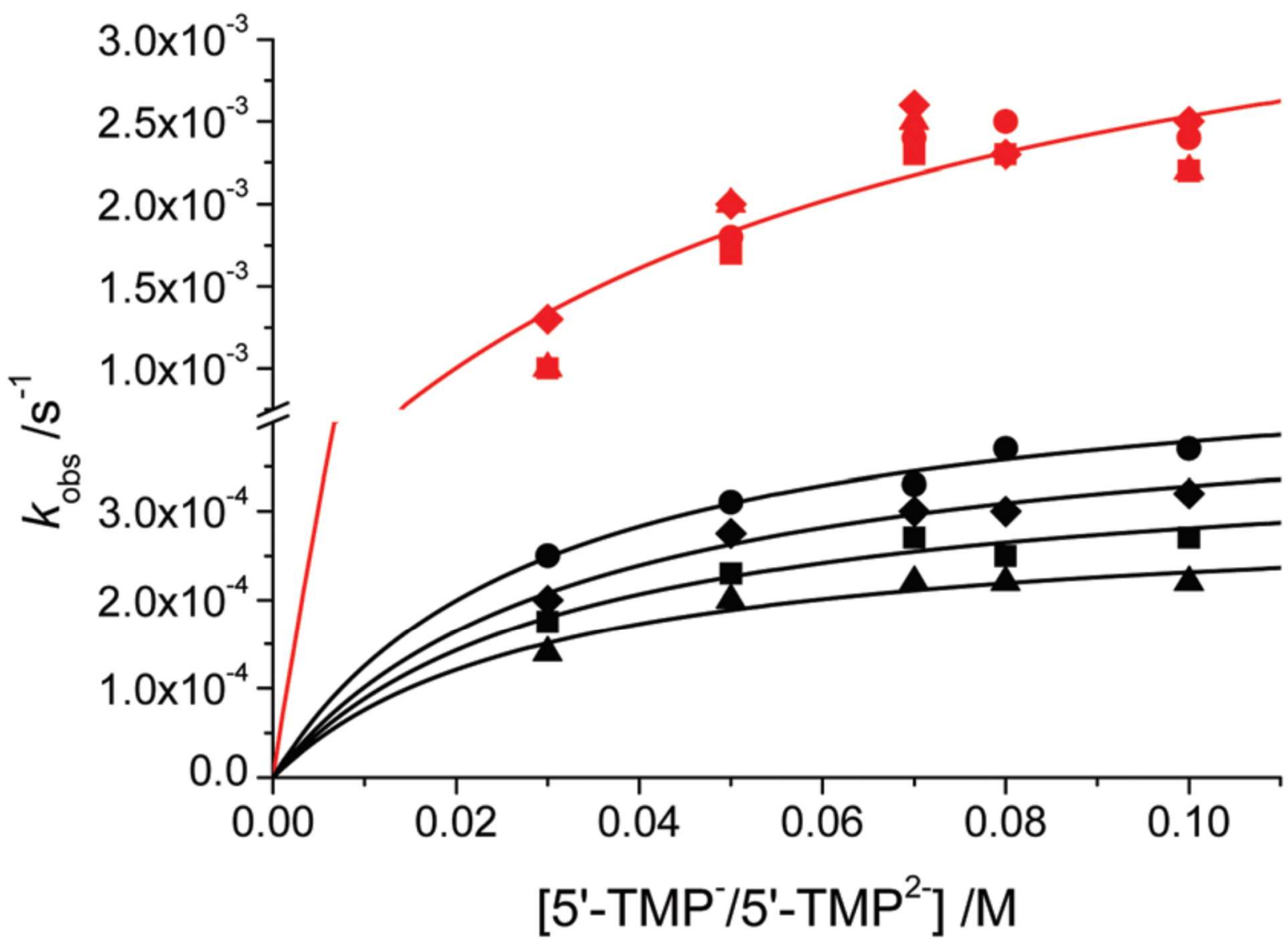



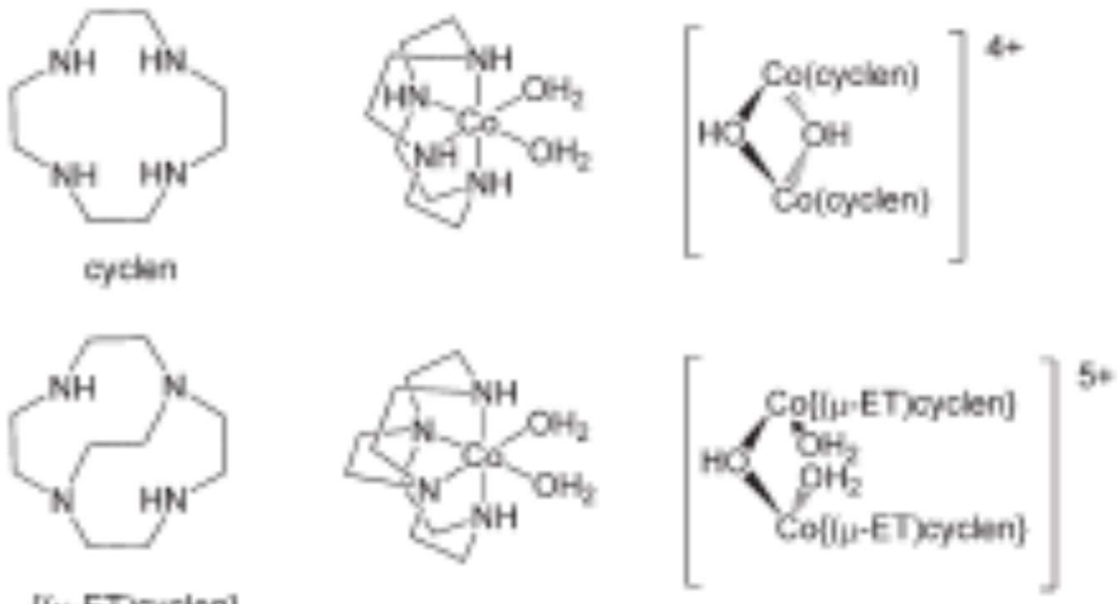

[in-ETjoychen]<smiles>CN1CCN2CCN(C)CCN(CC1)CC2</smiles>
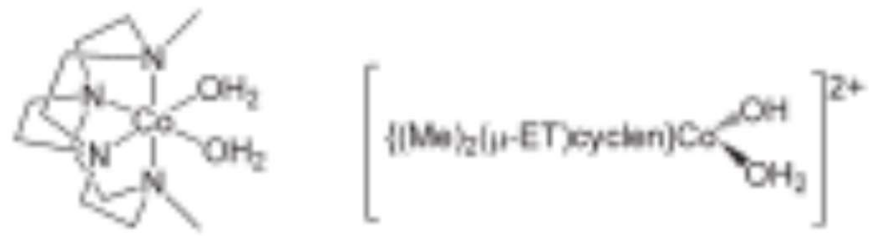

657

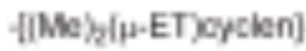

658

659

660

661 

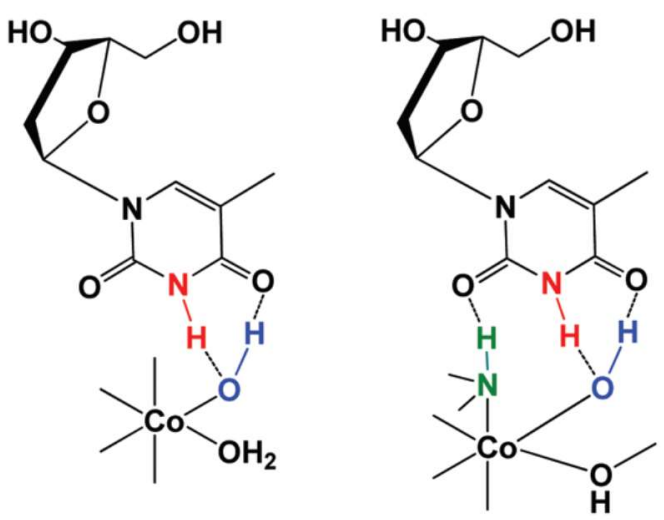

665
SCHEME 6

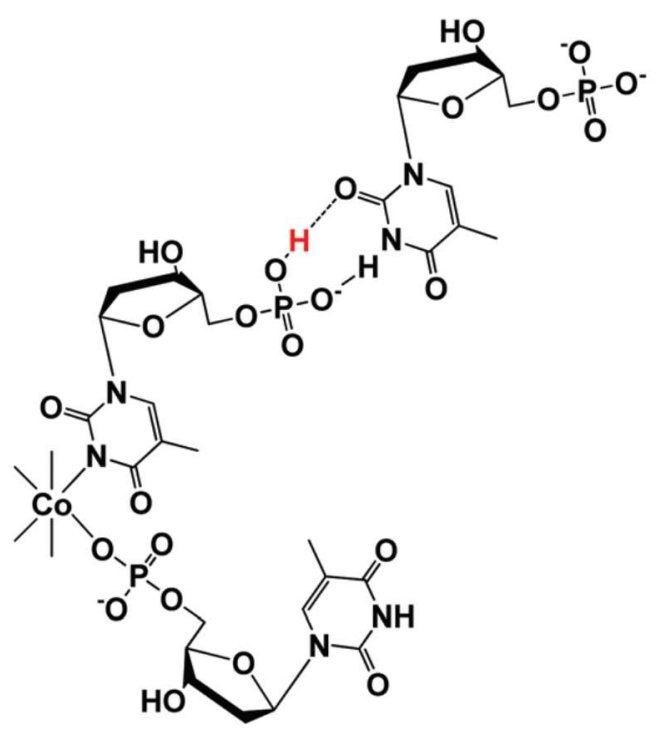


673 Table 1. Summary of the kinetic, thermal and pressure activation parameters for the reaction of $[\operatorname{Co}\{(\mu-$

674 ET)cyclen $\}(\mathrm{H} 2 \mathrm{O}) 2] 3+$ with phosphate, cytidine, thymidine, 5'-CMP and 5'-TMP at different pHs (0.4

675 M MES/HEPES, I = $1.0 \mathrm{NaClO} 4)$

676

677

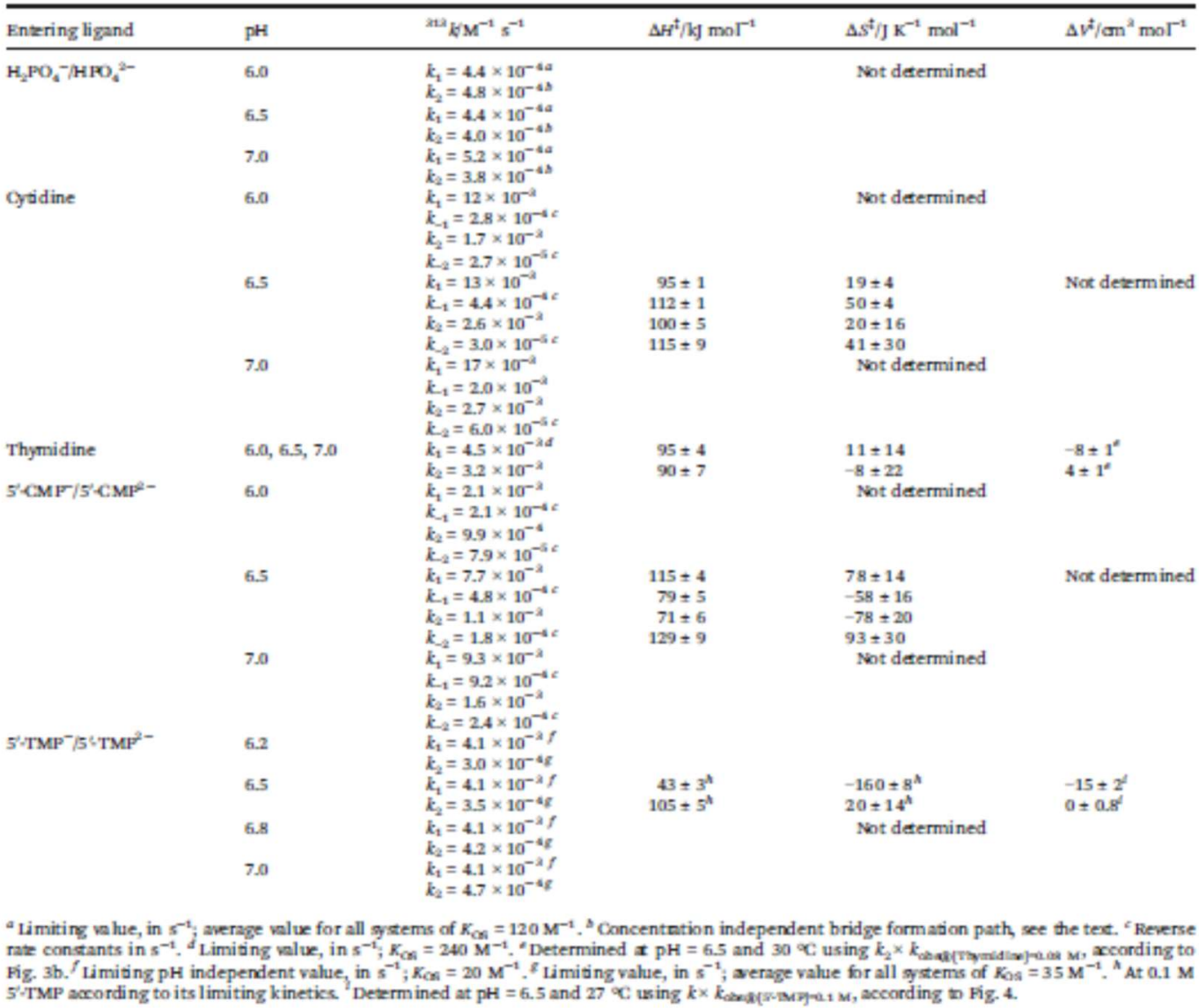

679

680

681 
682 Table 2 Crystal data and structure refinement for complex [Co $\{(\mu$-ET)-cyclen $\}(\mathrm{H} 2 \mathrm{O}) 2](\mathrm{CF} 3 \mathrm{SO} 3) 3$

683

\begin{tabular}{|c|c|}
\hline Empirical formula & $\mathrm{C}_{13} \mathrm{H}_{23} \mathrm{CoF}_{4} \mathrm{~N}_{4} \mathrm{O}_{2} \mathrm{~S}_{3}$ \\
\hline Formula weight & 758.50 \\
\hline Temperature & $100(2) \mathrm{K}$ \\
\hline Wavelength & $0.71073 \AA$ \\
\hline Crystal system & Monoclinic \\
\hline Space group & $P 21 / n$ \\
\hline Unit cell dimensions & $\begin{array}{l}a=9.0812(4) ; b=22.5814(13) ; \\
c=13.334 \alpha(7) \dot{A} \\
\alpha=90 ; \beta=95.368(2) ;=90^{\circ}\end{array}$ \\
\hline volume & $2722.4(2) A^{A}$ \\
\hline$z$ & 4 \\
\hline Dencity (calculated) & $1.851 \mathrm{Mg} \mathrm{m}^{-3}$ \\
\hline Abrorption mefficient & $0.985 \mathrm{~mm}^{-1}$ \\
\hline$F(000)$ & 1544 \\
\hline Crystal size & $0.299 \times 0.127 \times 0.107 \mathrm{~mm}^{2}$ \\
\hline$\theta$ range for data collection & 2.368 to $26.396^{\circ}$ \\
\hline Index ranges & $\begin{array}{l}-11 \leq h \leq 10,-28 \leq k \leq 28, \\
-16 \leq l \leq 16\end{array}$ \\
\hline Reflections ollected & 32892 \\
\hline Independent reflections & $5568[F($ int $)=0.046 .5]$ \\
\hline Complezness to $\theta=25.242^{\circ}$ & $99.7 \%$ \\
\hline Ahsorption correction & Semiempirical from equivalents \\
\hline Max, and min. tranamission & 0.7454 and 0.6885 \\
\hline Refinement method & Pull-matrix least-squares on $F^{2}$ \\
\hline Data/restraints/para meters & $5568 / 83 / 382$ \\
\hline Goodness-of fit on $F^{2}$ & 1.068 \\
\hline Final $R$ indices $[I>2 d(I)]$ & $R_{1}=0.0727, w R_{2}=0.1616$ \\
\hline$R$ indices (all data) & $R_{1}=0.0747, w R_{2}=0.1631$ \\
\hline Extinction mefficient & $\mathrm{n} / \mathrm{a}$ \\
\hline Largest diff. peak and hole & 1.812 and $-1.239 \mathrm{e}^{-a}$ \\
\hline CCDC code & 1400867 \\
\hline
\end{tabular}

